WASA Th: 70497

\title{
A SEARCH FOR GLOBAL AND SEASONAL VARIATION OF METHANE FROM NIMBUS 4 IRIS MEASUREMENTS
}

C. PRABHAKARA

G. DALU

V. G. KUNDE

OCTOBER 1973

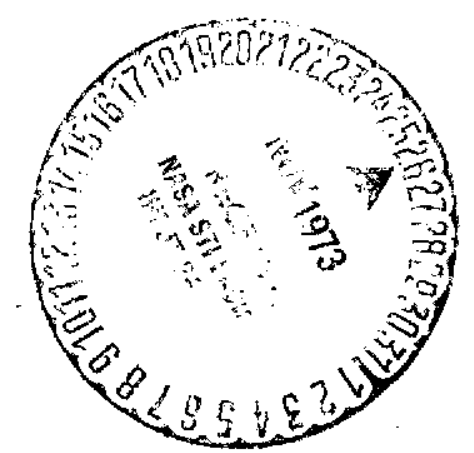

GSFC GODDARD SPACE FLIGHT CENTER GREENBELT, MARYLAND

(NASA-TH-X-70497) \& STACCH FOF GLOEAI HNC SESSONAL VAFIAITON CF HETHANE FRCM NIMEUS A IRIS GEASUGEOANS (NASA) 29 p HC $\$ 3.50$

CSCL ing

Unclas

if 7 - 10368 21567 


\title{
A SEARCH FOR GLOBAL AND SEASONAL VARIATION OF METHANE FROM NIMBUS 4 IRIS MEASUREMENTS
}

\author{
C. Prabhakara \\ G. Dalu \\ V. G. Kunde
}

October 1973

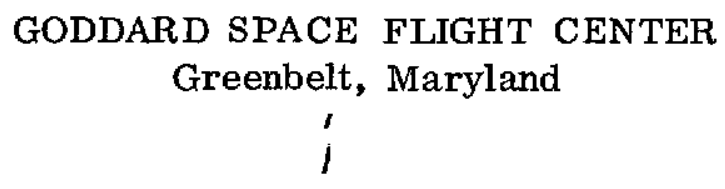


PRECEDING PAGE BLANK NOT FILMED

\title{
A SEARCH FOR GLOBAL AND SEASONAL VARIATION OF \\ METHANE FROM NIMBUS 4 IRIS MEASUREMENTS
}

\author{
C. Prabhakara, G. Dalu* and V. G. Kunde
}

\begin{abstract}
The Nimbus 4 Infrared Interferometer Spectrometer (IRIS) measurements in the region around $1304 \mathrm{~cm}^{-1}$ show absorption due to methane in the earth's atmosphere.
\end{abstract}

From the laboratory measurements of the absorption coefficient and a selected vertical distribution corresponding to $1.13 \mathrm{~atm} \mathrm{~cm}$ of methane, a theoretical model for the transmittance at $1304 \mathrm{~cm}^{-1}$ is developed. The weighting function deduced from this model shows a maximum around $300 \mathrm{mb}$. Some weak absorption due to nitrous oxide $\left(\mathrm{N}_{2} \mathrm{O}\right)$ in the atmosphere has been taken into account.

The vertical temperature profile, derived from the $15 \mu \mathrm{m} \mathrm{CO}_{2}$ band in the IRIS spectrum, together with the methane weighting function have been used in a consistent way to compute the upwelling intensity at $1304 \mathrm{~cm}^{-1}$. The brightness temperature corresponding to the IRIS observed radiance at $1304 \mathrm{~cm}^{-1}$ has been compared with the brightness temperature deduced from the calculated upwelling

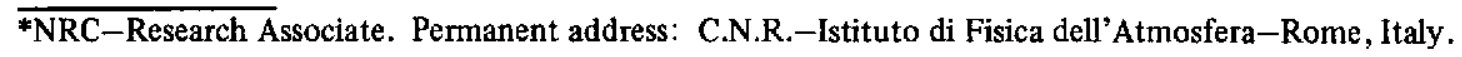


intensity from $80^{\circ}$ North to $80^{\circ}$ South and for different periods of the year. This comparison shows that the two brightness temperatures agree with one another to within the accuracy of measurements, about $2^{\circ} \mathrm{K}$ and that their difference reveals no geographic pattern. An error of $2^{\circ} \mathrm{K}$ in brightness temperature, relates to an error of $0.25 \mathrm{~atm} \mathrm{~cm}$ of methane. From this result we find that global or seasonal variability of methane is less than $\pm 0.25 \mathrm{~atm} \mathrm{~cm}$. 


\section{CONTENTS}

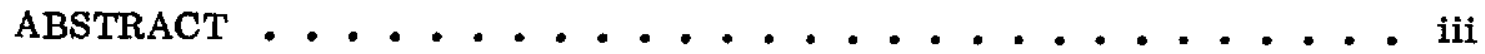

INTRODUCTION ..................... 1

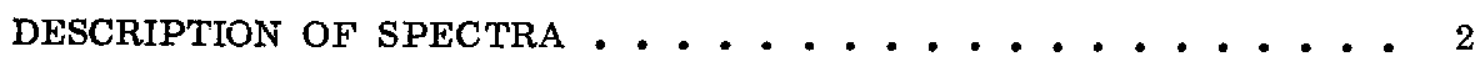

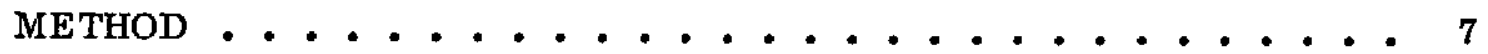

RESULTS ........................... 11

CONCLUSIONS ............................. 15

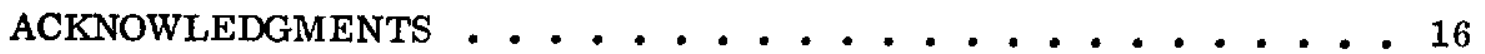

REFERENCES .................... 16

APPENDIX A-Statistical Band Model Parameters for $\mathrm{CH}_{4}$ and $\mathrm{N}_{2} \mathrm{O}$. . A A-1

\section{ILLUSTRATIONS}

$\underline{\text { Figure }}$

1 Observed IRIS Spectrum and the Computed Spectrum Including Only Water Vapour Absorption . . . . . . . 4

2 Absorption Spectra for Methane and Nitrous Oxide, and the Residual Spectrum $\Delta \mathrm{T} \ldots \ldots . \ldots 6$

3 Weighting Functions for Methane and Nitrous Oxide at $1304 \mathrm{~cm}^{-1}$.................. 10

4 Difference Between the Computed and the Observed Brightness Temperatures at $1304 \mathrm{~cm}^{-1} \ldots$. . . . . . 12

5 Comparison Between the Observed and the Calculated Brightness Temperatures . . . . . . . . 14 


\section{A SEARCH FOR GLOBAL AND SEASONAL VARIATION OF METHANE FROM NIMBUS 4 IRIS MEASUREMENTS}

\section{INTRODUCTION}

Methane is present in the earth's atmosphere as a minor constituent (Migeotte, 1948). Measurements of the total amount of methane and its vertical distribution derived from balloon and rocket flights (Ehhalt and Heidt, 1973; For short summary see Drayson et al., 1972, and also Friend, 1972) indicate the mixing ratio of methane in the atmospheric layers near the surface changes from about 0.6 to $2.0 \mathrm{ppm}$ by volume. In the troposphere this gas appears to be well mixed with a mixing ratio of about $1.41 \mathrm{ppm}$. Above the tropopause the mixing ratio decreases reaching a value of $\sim 0.25 \mathrm{ppm}$ near $50 \mathrm{~km}$ altitude. The total amount of the gas per unit area corresponding to an average mixing ratio of $1.41 \mathrm{ppm}$ is about $1.13 \mathrm{~atm} \mathrm{~cm}$.

The main source of methane is on land from the decomposition of organic matter (Koyama, 1963) with no known sources in the atmosphere. Atmospheric photochemical investigations suggest oxidation of methane as a sink, both in the troposphere (Weinstock and Nicki, 1972) and in the stratosphere (McConnell et al., 1972, Wof sy, etal., 1972). Because methane is produced on land, a variation with geographic location, or at least an asymmetry between the northern and southern hemisphere would be expected. However, the mean atmospheric residence times of 1-7 years derived from photochemical theories (Weinstock and Nicki, 1972; Wofsy, 
et al. , 1972; Junge, 1972; Wofsy and McElroy, 1973) should be sufficiently long to smooth out any source variations and distribute the gas uniformly over the globe.

The available measurements on methane concentration, made with different measuring techniques and confined to limited geographic regions, are not sufficient to present a comprehensive picture of the temporal and spatial variation of methane in the earth's atmosphere. Remote sensing satellite instruments are ideally suited to examine the large scale variability of methane. Measurements made by the Infrared Interferometer Spectrometer (IRIS), aboard the Nimbus 3 and Nimbus 4 satellites, clearly show the absorption features produced by methane in the atmosphere in the $1225-1325 \mathrm{~cm}^{-1}$ region (Conrath et al., 1970; Hanel and Conrath, 1970). These satellite measurements covered the globe from $80^{\circ} \mathrm{N}$ to $80^{\circ} \mathrm{S}$ and in the case of Nimbus 4 satellite were available for about one year.

In this investigation the Nimbus IV IRIS spectra have been examined for any global or seasonal deviations of methane from its mean value of $1.41 \mathrm{ppm}$.

\section{DESCRIPTION OF SPECTRA}

The Infrared Interferometer Spectrometer (IRIS) measured the thermal emission of the earth's atmosphere and surface from $400-1600 \mathrm{~cm}^{-1}$ with an apodized spectral resolution of $2.8 \mathrm{~cm}^{-1}$. The instrument and its performance have been described by Hanel, et al., 1972, together with the instrumental calibration and an overview of some observed spectra. The radiometric precision of the instrument 
is high with the noise equivalent radiance (NER) of $\sim 0.5 \mathrm{erg} \mathrm{sec}^{-1} \mathrm{~cm}^{-2} \mathrm{sr}^{-1} /$ $\mathrm{cm}^{-1}$ as estimated from the in-flight calibration.

Absorption features of $\nu_{4}$ fundamental vibration rotation band of methane have been observed in the $1225-1325 \mathrm{~cm}^{-1}$ region of the IRIS spectra. This band has a narrow $Q-b r a n c h$ with intense absorption around $1304 \mathrm{~cm}^{-1}$. An observed brightness temperature spectrum of IRIS, in the $1200-1350 \mathrm{~cm}^{-1}$ region, taken over the Pacific ocean near Guam on April 27, 1970 is shown in Figure 1 to illustrate this strong feature. This spectral feature is easily noticeable in the IRIS spectra taken over the globe from $80^{\circ} \mathrm{N}$ to $80^{\circ} \mathrm{S}$.

From an examination of the observed brightness temperature spectrum in Figure 1 one can readily notice the presence of several lines of water vapour superimposed on the methane band. To appreciate quantitatively the water vapour interference a theoretical spectrum resulting purely from water vapour absorption is calculated with the help of temperature and relative humidity measurements made by a radio-sonde at Guam. Detailed line by line direct integration slant path program is used for this purpose. The theoretical brightness temperature spectrum obtained from such a calculation is shown in Figure 1. From a comparison of these two spectra one can see that the spectral region $1200-1350 \mathrm{~cm}^{-1}$ is profoundly influenced by the water vapour lines with the exception of several narrow water vapour windows. The presence of one water vapour window particularly at $1300 \mathrm{~cm}^{-1}$ favours the Q-branch of the $\mathrm{CH}_{4}$ band to manifest itself in the IRIS spectra. 


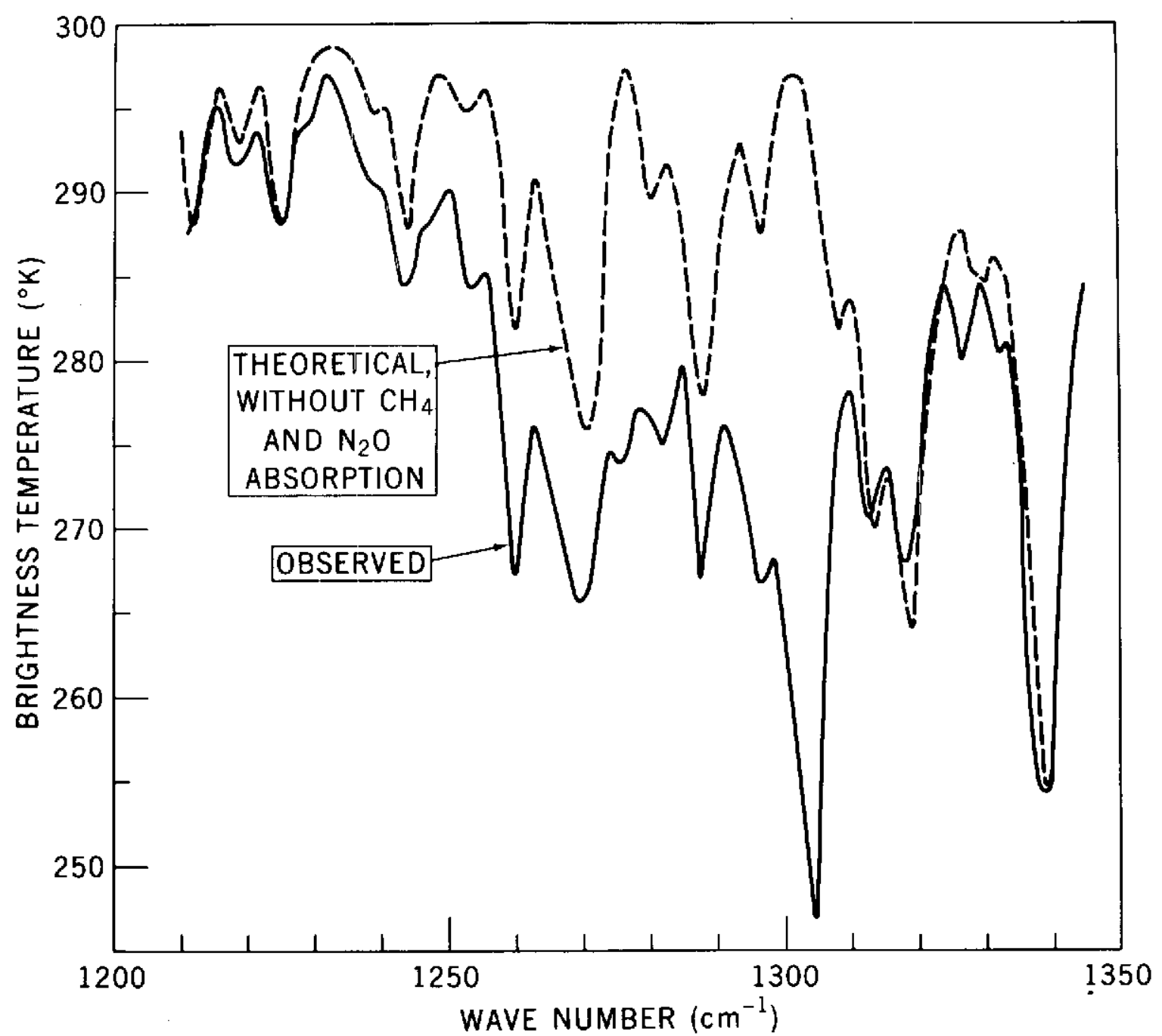

Figure 1. Observed IRIS Spectrum and the Computed Spectrum Including Only Water Vapour Absorption 
The water vapour absorption in the observed spectrum can be eliminated by taking the difference between the two brightness temperature spectra shown in Figure 1. This difference or "residual" spectrum $\Delta T$, as shown in Figure 2, can then be examined for many absorption features that are weaker than the $Q-$ branch of $\mathrm{CH}_{4}$. In the spectral region $1200-1350 \mathrm{~cm}^{-1}$ the $\nu_{1}$ band of $\mathrm{N}_{2} \mathrm{O}$, another known minor constituent of the atmosphere, also produces absorption. For this reason the $\mathrm{CH}_{4}$ and $\mathrm{N}_{2} \mathrm{O}$ features in the residual spectrum are scrutinized with the help of the absorption bands of these two gases which are included in Figure 2. These absorption bands are calculated with the band model parameters described in Appendix A. To simulate the atmospheric conditions in these calculations the pressure is taken as $500 \mathrm{mb}$, and the assumed $\mathrm{CH}_{4}$ and $\mathrm{N}_{2} \mathrm{O}$ path lengths are $1.13 \mathrm{~cm}$ and $0.25 \mathrm{~cm}$ respectively.

In the methane $\nu_{4}$ fundamental band the rotational lines for each rotational quantum number $(J)$ of the $P$ - and $R$-branches are spaced $\sim 5 \mathrm{~cm}^{-1}$ apart. A general correspondence between the calculated methane band and the residual spectrum (see Fig. 2) is evident. The P- and R-branches of the $\nu_{1}$ band of $\mathrm{N}_{2} \mathrm{O}$ produce absorption peaks at 1276 and $1304 \mathrm{~cm}^{-1}$ respectively. The residual spectrum also reflects the presence of these features. As the mean line spacing of $\mathrm{N}_{2} \mathrm{O}$ is $\sim 0.8 \mathrm{~cm}^{-1}$ individual $\mathrm{N}_{2} \mathrm{O}$ lines are not identifiable in the spectrum. 


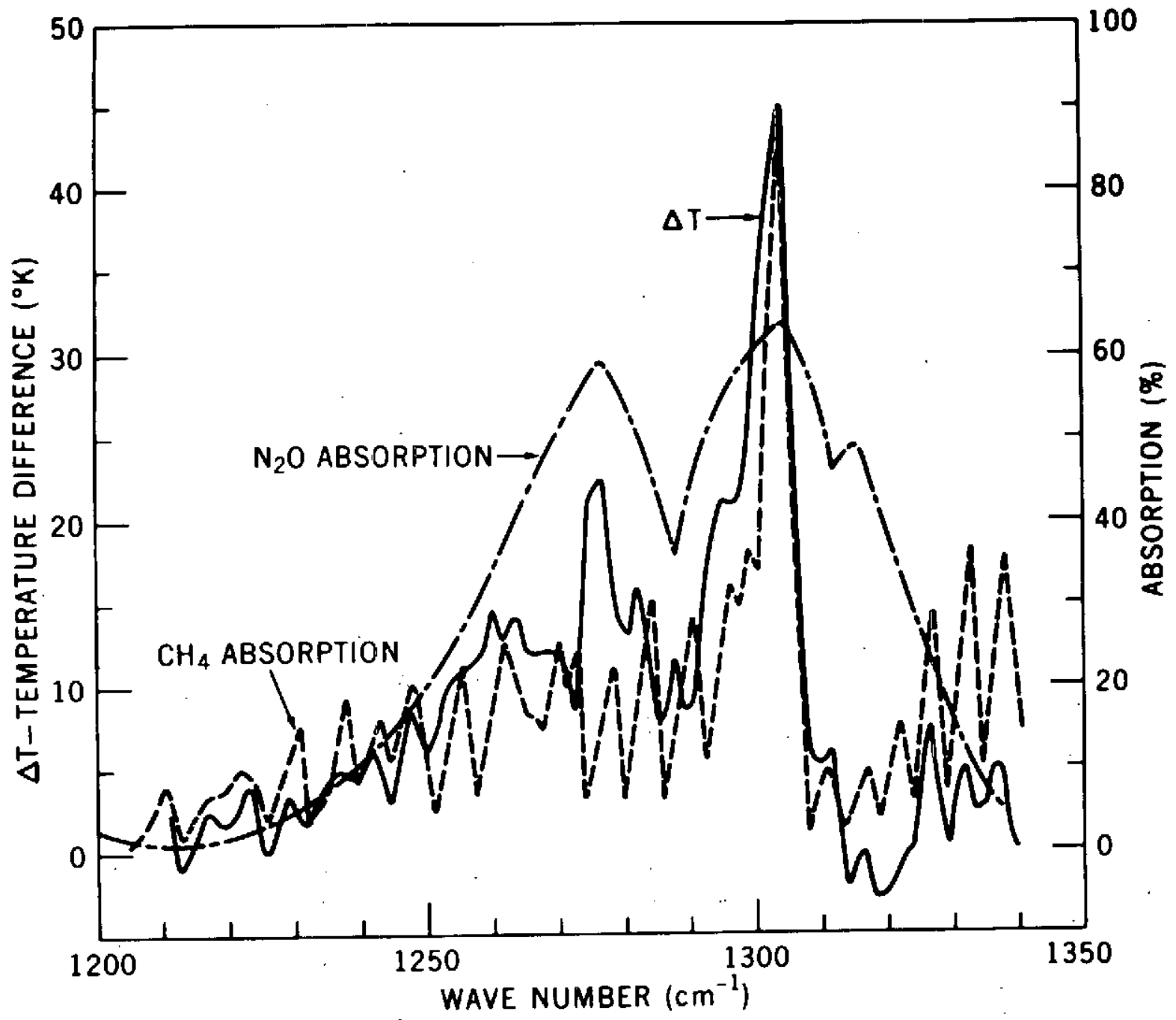

Figure 2. Absorption Spectra for Methane and Nitrous Oxide, and the Residual Spectrum $\Delta T$ 


\section{METHOD}

Remote sensing of a minor gaseous constituent in the earth's atmosphere, from thermal infrared measurements, is feasible when that gas produces measurable absorption. It is, however, necessary to have simultaneously a temperature sounding of the atmosphere to make a quantitative estimate of the amount of the gas. In addition, if we wish to measure the global or seasonal variability of the gas with a meaningful accuracy, the absorption due to other variable atmospheric gases, particularly the water vapour, should not adversely interfere. Success in remote sensing of the global distribution of ozone (Prabhakara, et al., 1970), from the 9.6 $4 \mathrm{~m}$ IRIS measurements, in the presence of some water vapour absorption supports this point of view.

In this study, we make an estimation of the $\mathrm{CH}_{4}$ amount from the $1304 \mathrm{~cm}^{-1}$ Q-branch feature. A radiative transfer model is developed for this purpose.

From the radiative transfer formalism, in a non-scattering atmosphere under local thermodynamic equilibrium we can relate the upwelling intensity I $(\nu)$ as

$$
\mathrm{I}(\nu)=\mathrm{B}\left(\nu, \mathrm{T}\left(\mathrm{p}_{0}\right)\right) \tau\left(\nu, \mathrm{p}_{0}\right)+\int_{\tau\left(\nu, \mathrm{p}_{0}\right)}^{1} \mathrm{~B}(\nu, \mathrm{T}(\mathrm{p})) \mathrm{d} \tau(\nu, \mathrm{p})
$$

where $p_{0}$ and $p$ are surface pressure and pressure at any height $(\mathrm{mb})$,

$\nu$ is the wave number $\left(\mathrm{cm}^{-1}\right)$,

$\mathrm{T}$ is the temperature $(\mathrm{K})$, 
$B$ is the Planck intensity,

$\tau$ is the transmission from any pressure level $p$ to the top of the atmosphere. The temperature sounding $T(p)$ needed in Equation 1 is obtained by performing an inversion of the IRIS measurements in the $667 \mathrm{~cm}^{-1} \mathrm{CO}_{2}$ band (Conrath, et al., 1972). The transmission function $\tau=\tau_{\mathrm{N}_{2} \mathrm{O}} * \tau_{\mathrm{CH}_{4}}$ is calculated with the band model parameters of $\mathrm{CH}_{4}$ and $\mathrm{N}_{2} \mathrm{O}$ given in Appendix A. For the purpose of these calculations, it is assumed that in the lower atmosphere up to about $100 \mathrm{mb} \mathrm{CH}_{4}$ has a constant mixing ratio of $1.41 \mathrm{ppm}$ and above $100 \mathrm{mb}$ the mixing ratio decreases linearly with respect to height to $0.25 \mathrm{ppm}$ at $50 \mathrm{~km}$ level (Ehhalt and Heidt, 1973). $\mathrm{N}_{2} \mathrm{O}$ is assumed to be uniformly mixed with a mixing ratio of $0.3 \mathrm{ppm}$. In Table 1 the distribution of the gases and the calculated transmission functions for $1304 \mathrm{~cm}^{-1}$ are tabulated.

In Figure 3 the weighting function, $d \tau / d$ lnp for each gas and for both gases is shown. The emission of $\mathrm{N}_{2} \mathrm{O}$ primarily originates from the lowest layers in the atmosphere where the water vapour is present. Water vapour absorption, although weak, can range from a maximum of about $50 \%$ in the tropics to less than $20 \%$ at high latitudes. Thus the $\mathrm{N}_{2} \mathrm{O}$ information at $1304 \mathrm{~cm}^{-1}$ is damaged by water vapour absorption. At $1276 \mathrm{~cm}^{-1}$, atmospheric $\mathrm{N}_{2} \mathrm{O}$ has about the same absorption as that at $1304 \mathrm{~cm}^{-1}$ (see Table 1) and so the weighting function for $\mathrm{N}_{2} \mathrm{O}$ in this spectral region also has a maximum near the surface. The water vapour absorption in the lower atmosphere precludes the possibility of measuring $\mathrm{N}_{2} \mathrm{O}$ either from 1304 or from $1276 \mathrm{~cm}^{-1}$. For this reason we have 
Table 1

\begin{tabular}{|c|c|c|c|c|c|c|c|}
\hline $\begin{array}{l}\text { Pressure } \\
(\mathrm{mb})\end{array}$ & $\begin{array}{c}\mathrm{CH}_{4} \text { Path } \\
\text { Length } \\
\text { (atm cm) }\end{array}$ & $\begin{array}{l}\mathrm{N}_{2} \mathrm{O} \text { Path } \\
\text { Length } \\
\text { (atm } \mathrm{cm})\end{array}$ & $\begin{array}{c}\mathrm{CH}_{4} \text { Trans- } \\
\text { missivity at } \\
1304 \mathrm{~cm}^{-1}\end{array}$ & $\begin{array}{c}\mathrm{N}_{2} \mathrm{O} \text { Trans- } \\
\text { missivity at } \\
1304 \mathrm{~cm}^{-1}\end{array}$ & $\begin{array}{c}\text { Total } \\
\text { Transmissivity } \\
\text { at } 1304 \mathrm{~cm}^{-1}\end{array}$ & $\begin{array}{c}\text { Total } \\
\text { Transmissivity } \\
\text { at } 1276 \mathrm{~cm}^{-1}\end{array}$ & $\begin{array}{c}\text { Height } \\
(\mathrm{km})\end{array}$ \\
\hline 3.7 & 0.0011 & 0.0009 & 0.995 & 0.996 & 0.992 & 0.996 & 38.2 \\
\hline 5.5 & 0.0023 & 0.0014 & 0.992 & 0.994 & 0.987 & 0.994 & 35.2 \\
\hline 8.2 & 0.0045 & 0.0020 & 0.987 & 0.992 & 0.979 & 0.991 & 32.6 \\
\hline 12.2 & 0.0081 & 0.0030 & 0.979 & 0.988 & 0.967 & 0.987 & 29.9 \\
\hline 18.2 & 0.0143 & 0.0045 & 0.967 & 0.981 & 0.949 & 0.980 & 27.2 \\
\hline 27.2 & 0.0244 & 0.0068 & 0.947 & 0.972 & 0.921 & 0.969 & 24.6 \\
\hline 40.5 & 0.0410 & 0.0101 & 0.918 & 0.959 & 0.881 & 0.954 & 22.0 \\
\hline 60.5 & 0.0683 & 0.0151 & 0.877 & 0.940 & 0.824 & 0.932 & 19.4 \\
\hline 90.4 & 0.1020 & 0.0226 & 0.822 & 0.911 & 0.750 & 0.900 & 16.9 \\
\hline 134.9 & 0.1520 & 0.0337 & 0.747 & 0.871 & 0.650 & 0.855 & 14.3 \\
\hline 201.4 & 0.2280 & 0.0503 & 0.647 & 0.813 & 0.526 & 0.791 & 11.8 \\
\hline 300.6 & 0.3400 & 0.0751 & 0.522 & 0.734 & 0.383 & 0.705 & 9.1 \\
\hline 448.8 & 0.5070 & 0.1120 & 0.379 & 0.631 & 0.239 & 0.593 & 6.4 \\
\hline 669.9 & 0.7570 & 0.1670 & 0.235 & 0.503 & 0.118 & 0.458 & 3.3 \\
\hline 1000.0 & 1.1300 & 0.2500 & 0.115 & 0.358 & 0.041 & 0.312 & 0.1 \\
\hline
\end{tabular}




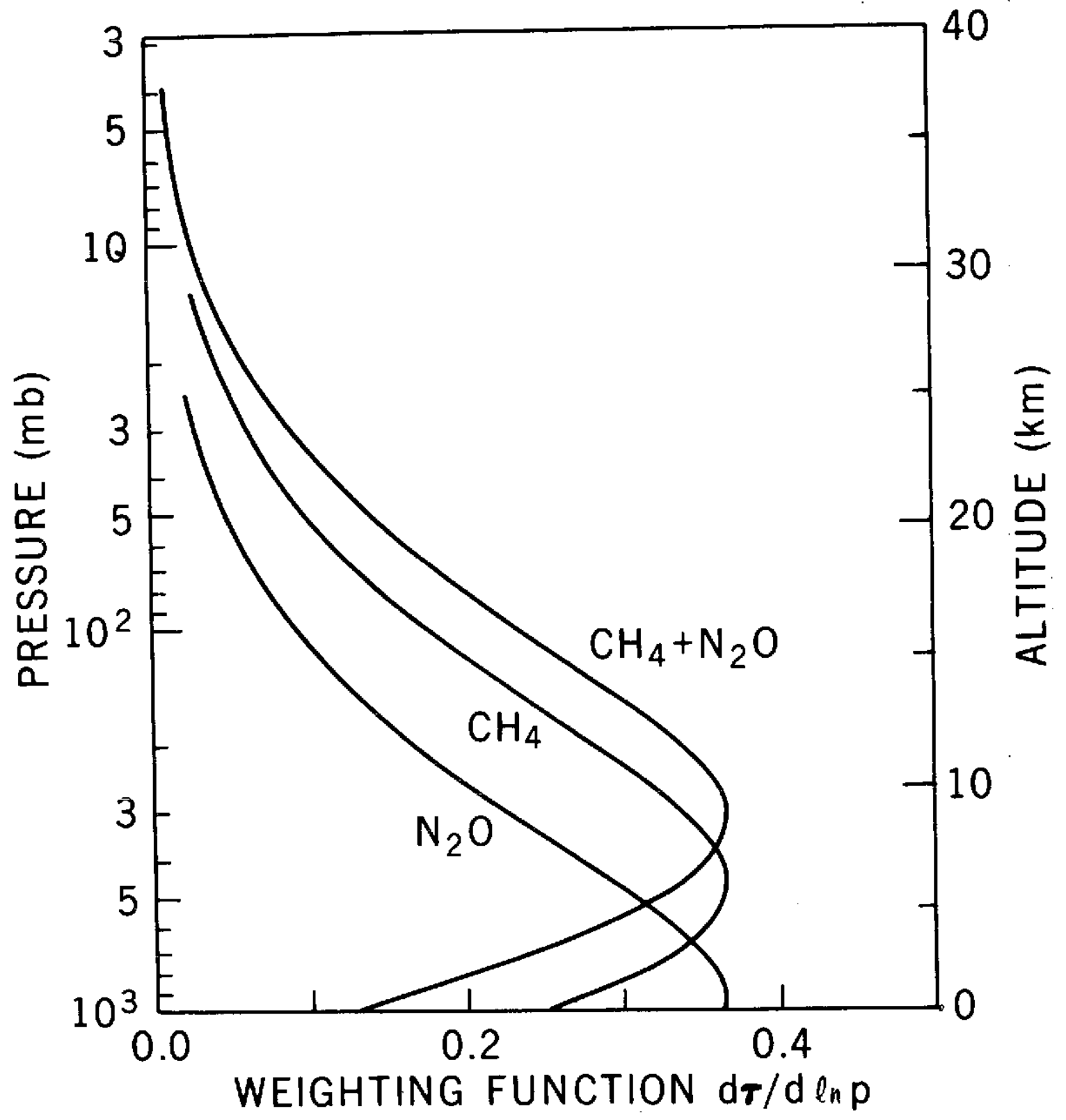

Figure 3. Weighting Functions for Methane and Nitrous Oxide at $1304 \mathrm{~cm}^{-1}$ 
assumed the mixing ratio of $\mathrm{N}_{2} \mathrm{O}$ in the atmosphere is $0.3 \mathrm{ppm}$ (corresponding to $0.25 \mathrm{~atm} \mathrm{~cm}$ ) invariable with respect to time and geographic location. However, large part of the methane information originates around $450 \mathrm{mb}$ as can be seen from Figure 3, which is considerably separated from the water vapour in the lower atmosphere. Thus the $1304 \mathrm{~cm}^{-1}$ measurements can yield some information about methane.

In the present study the spectral measurements at $1304 \mathrm{~cm}^{-1}$ are examined for deviations of $\mathrm{CH}_{4}$ from the global mean value of $1.13 \mathrm{~cm}$ atm in the following fashion. Synthetic radiances are computed at $1304 \mathrm{~cm}^{-1}$ from Equation 1, using $\mathrm{T}$ (p) from the inversion of the $667 \mathrm{~cm}^{-1} \mathrm{CO}_{2}$ band. The $\mathrm{CH}_{4}$ and $\mathrm{N}_{2} \mathrm{O}$ transmission functions (see Table 1) used in these calculations correspond to the total amounts of 1.13 and $0.25 \mathrm{~cm}$ atm, respectively. The $1304 \mathrm{~cm}^{-1}$ calculated radiance and the corresponding brightness temperature are compared with the IRIS observed data. The difference between the observed and calculated brightness temperatures can be related to the deviation of methane amount from its global mean.

\section{RESULTS}

The difference in the observed and computed brightness temperature, $\delta \mathrm{T}$, is shown in Figure 4 for orbit 1207 , July 7,1970 , going from $80^{\circ} \mathrm{N}$ to $80^{\circ} \mathrm{S}$. The $\delta \mathrm{T}$ shown has a standard deviation of $2.5^{\circ} \mathrm{K}$ and reveals no latitudinally dependent variation. The data corresponding to large $\delta \mathrm{T}$ are associated with high clouds. 


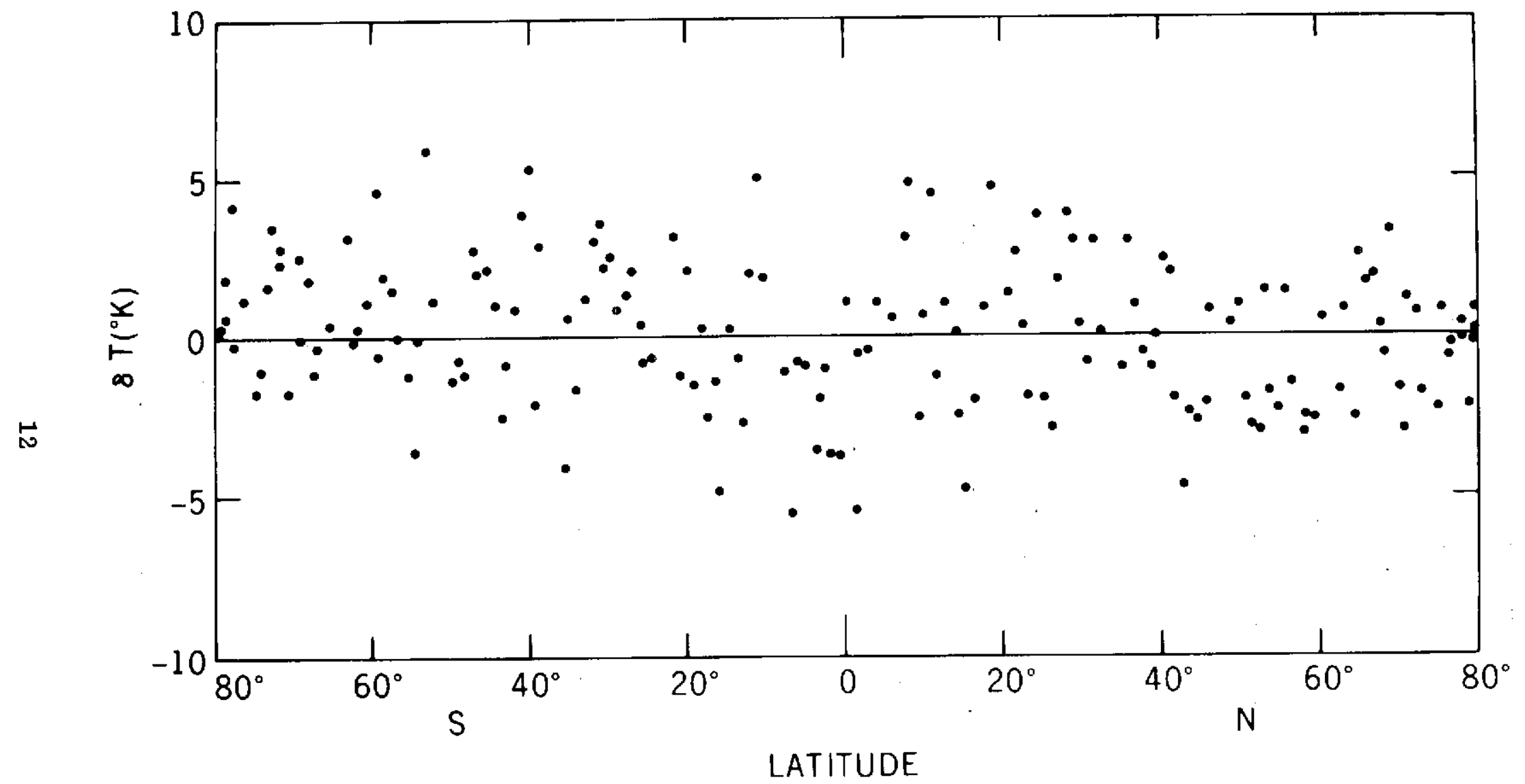

Figure 4. Difference Between the Computed and the Observed Brightness Temperatures at $1304 \mathrm{~cm}^{-1}$ 
The $15 \mu \mathrm{m} \mathrm{CO}$ temperature soundings derived from spectra contaminated by high clouds are in considerable error and so are the upwelling intensities calculated at $1304 \mathrm{~cm}^{-1}$ using such temperature data. However, when the clouds are at lower levels in the atmosphere these errors are reduced.

In further analysis of IRIS data we have eliminated high cold cloud contaminated spectra. These high cold clouds can be easily identified from the $900 \mathrm{~cm}^{-1}$ (11 $\mu \mathrm{m})$ IRIS window measurements. When the high altitude cloud contaminated data are not considered the $\delta \mathrm{T}$ shown in Figure 4 has a standard deviation of about $2^{\circ} \mathrm{K}$. This error is comparable to the noise equivalent temperature (NET) of IRIS measurements at $1304 \mathrm{~cm}^{-1}$. The model calculations indicate that in order to change the brightness temperature by $\pm 2^{\circ} \mathrm{K}$ the mixing ratio of methane should be changed by $\pm 0.25 \mathrm{ppm}$. This result implies the sensitivity in measuring $\mathrm{CH}_{4}$ from IRIS data is about $\pm 25 \%$ of the global mean value.

With this technique we have processed Nimbus 4 IRIS data to examine if there are any organized patterns in $\delta \mathrm{T}$ over the globe on a daily or monthly mean basis. We find from this study that there are no organized patterns in methane distribution.

These results can be demonstrated from the scatter diagram shown in Figure 5 where the calculated brightness temperature and the observed brightness temperature at $1304 \mathrm{~cm}^{-1}$ are plotted for different geographic areas and for different seasons. The brightness temperatures range from $225^{\circ} \mathrm{K}$ near the polar regions to $255^{\circ} \mathrm{K}$ in the tropics. If the calculated and observed brightness 

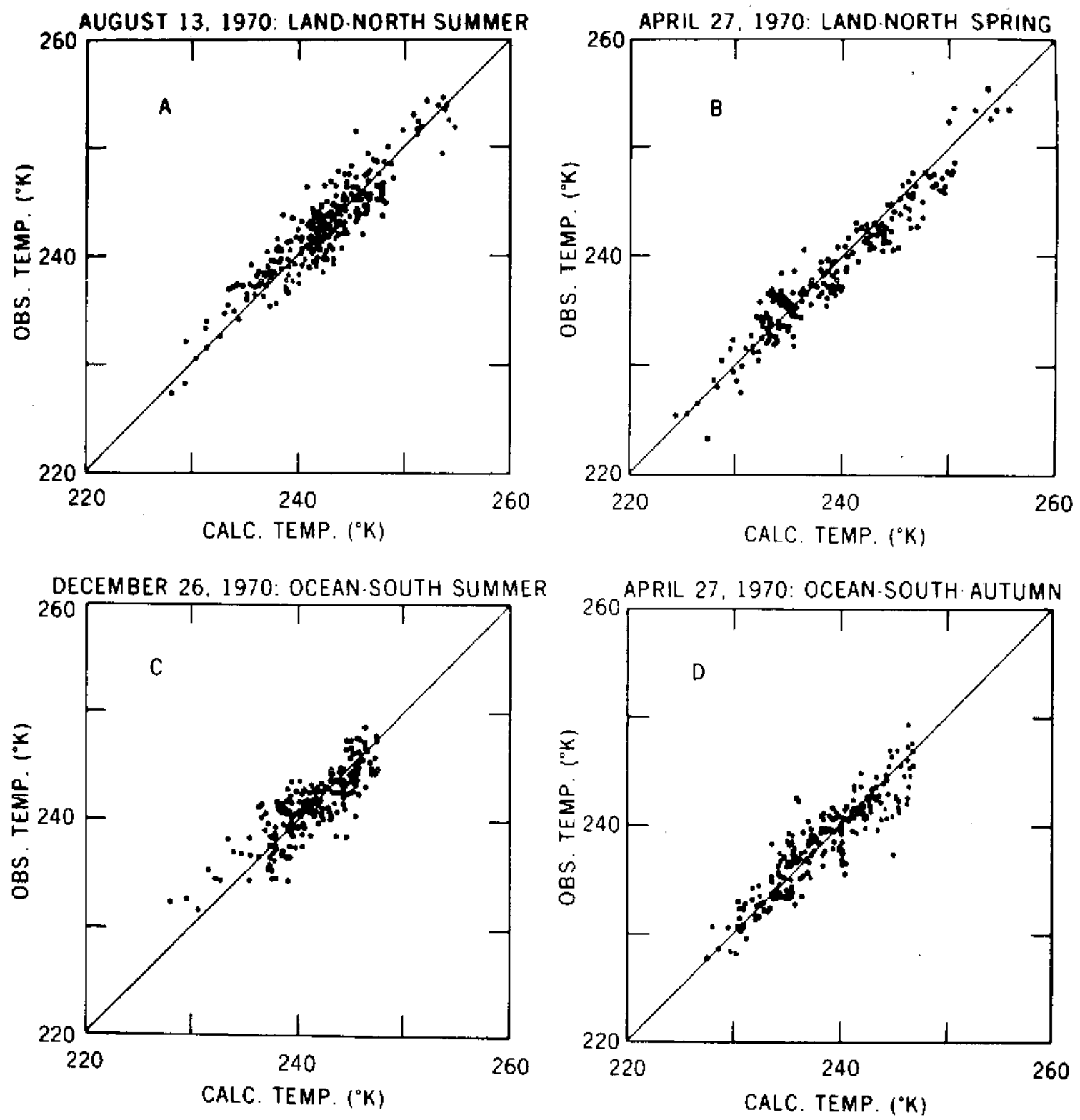

Figure 5. Comparison Between the Observed and the Calculated Brightness Temperatures 
temperatures are equal the data points in Figure 5 should fall on the line having $45^{\circ}$ slope. If there is more methane than $1.13 \mathrm{~atm} \mathrm{~cm}$, we should find the observed brightness temperature systematically colder than the calculated one. From Figure 5a and 5b, representing the variability of methane over land, we see the data closely follows the line having $45^{\circ}$ slope. Similar results are found from the oceanic cases shown in Figure $5 \mathrm{c}$ and $5 \mathrm{~d}$.

The standard deviation of the data in all these cases with respect to the $45^{\circ}$ line is about $2^{\circ} \mathrm{K}$. Further in all these cases the scatter of the data does not suggest any systematic increase of decrease in mixing ratio with respect to latitude or season.

\section{CONCLUSIONS}

In the present study, information on the global distribution of methane from a satellite is obtained for the first time. The results obtained over the land, where the sources of methane are present, show no appreciable differences from the results obtained over the ocean. Also no seasonal variation has been detected. From this study it can be stated that there is no global or seasonal variability of methane to within an accuracy of $0.25 \mathrm{ppm}$. This suggests that methane has a life time long enough to produce a uniform global distribution.

Remote measurements at high spectral resolution $\left(\sim 0.1 \mathrm{~cm}^{-1}\right)$, which can isolate the absorption features of $\mathrm{H}_{2} \mathrm{O}, \mathrm{CH}_{4}$ and $\mathrm{N}_{2} \mathrm{O}$, would permit one to 
measure the global and seasonal variability of $\mathrm{CH}_{4}$, with an accuracy better than the \pm 0.25 ppm limits set by the Nimbus 4 IRIS measurements. Additionally the higher spectral resolution may be useful in the determination of the vertical distribution of $\mathrm{CH}_{4}$ and the total amount of $\mathrm{N}_{2} \mathrm{O}$.

\section{ACKNOWLEDGMENTS}

The authors are grateful to Drs. R. A. Hanel, B. J. Conrath, R. Wexler for their constructive criticism and comments.

\section{REFERENCES}

Blaine, R. L. and W. A. Hovis, Private Communication, NASA-GSFC, Greenbelt, 1973.

Burch, D. E., D. A. Gryvnak, E. B. Singleton, W. L. France, and D. Williams, Infrared Absorption by $\mathrm{CO}_{2}$, Water Vapour, and Minor Atmospheric Constituents - AFCRL - 62 - 698, Air Force Cambridge Res. Labs., 1962.

Conrath, B. J., R. A. Hanel, V. G. Kunde, and C. Prabhakara, The Infrared Interferometer Experiment on Nimbus 3, J. Geophys. Res., 75, 5831 $5857,1970$.

Conrath, B. J., Vertical Resolution of Temperature Profiles Obtained from Remote Radiation Measurements, J. Atmos. Sci., 29, 1262-1271, 1972. 
Drayson, S. R., F. L. Bartman, W. R. Kuhn, and R. Tallamraju, Satellite Measurement of Stratospheric Pollutants and Minor Constituents by Solar Occultation: A Preliminary Report, The University of Michigan, Report $011023-1-\mathrm{T}, 1972$.

Ehhait, D. H. and L. E. Heidt, Vertical Profiles of $\mathrm{CH}_{4}$ in the Troposphere and Stratosphere, J. Geophys. Res., 78, 5265-5271, 1973.

Friend, J. P., Trace material composition of the lower stratosphere, Climatic Impact Assessment Program, Proceedings of the Survey Conference, DOT TSC - OST - 72-73, 1972 .

Goody, R. M. and T. W. Wormell, The quantitative determination of atmospheric gases by infrared spectroscopic methods, Royal Society of London, Proceedings, 209, 178-196, 1951 .

Goody, R. M., Atmospheric Radiation I. Theoretical Basis, Oxford, Claredon Press, 1964.

Hanel, R. A. and B. J. Conrath, Thermal Emission Spectra of the Earth and Atmosphere from the Nimbus 4 Michelson Interferometer Experiment, Nature, 228, 143-145, 1970 .

Hanel, R. A., B. J. Conrath, V. G. Kunde, C. Prabhakara, I. Revah, V. V. Salomonson, and G. Wolford, The Nimbus 4 Infrared Spectroscopy Experiment, J. Geophys. Res., 77, 2629-2641, 1972. 
Junge, C., The cycle of atmospheric gases - natural and man made, Quart. J. R. Met. Soc., 98, 711-729, 1972.

Koyama, T., Gaseous Metabolism in Lake Sediments and Paddy Soils and the Production of Atmospheric Methane and Hydrogen, J. Geophys. Res., 68, $3971-3973,1963$.

McConnell, J. C., M. B. McElroy, and S. C. Wofsy, Natural sources of atmospheric CO, Nature, 233, 187-188, 1972.

Migeotte, M., Methane in the earth's atmosphere, Astrophys. J., 107, 400-403, 1948.

Nielsen, A. H. and H. H. Nielsen, The Infrared Absorption Bands of Methane, Physical Review, 48, 864-867, 1935.

Prabhakara, C., B. J. Conrath, R. A. Hanel, and E. J. Williamson, Remote Sensing of Atmospheric Ozone Using the 9.6 $\mu \mathrm{m}$ Band, Jour. of Atm. Sciences, 27, 689-697, 1970 .

Varanasi, P. and G. D. T. Tejwani, Experimental and Theoretical Studies on Collision - Broadend lines in the $\nu_{4}$ - Fundamental of Methane, J. Q.S.R. T., 12, 849-855, 1972.

Weinstock, B. and R. Nicki, Carbon monoxide in nature, Science, 176, 290$292,1972$. 
Wofsy, S. C., J. C. McConnell, and M. B. McElroy, Atmospheric $\mathrm{CH}_{4}$, CO, and $\mathrm{CO}_{2}$, J. Geophys. Res., 77, 4477-4493, 1972.

Wofsy, S. C. and M. B. McElroy, On vertical mixing in the upper stratosphere and lower mesosphere, J. Geophys. Res., 78, 2619-2624, 1973. 


\section{LIST OF ILLUSTRATIONS}

Figure 1. Observed IRIS Spectrum and the Computed Spectrum Including Only Water Vapour Absorption

Figure 2. Absorption Spectra for Methane and Nitrous Oxide, and the Residual Spectrum $\Delta \mathrm{T}$

Figure 3. Weighting Functions for Methane and Nitrous Oxide at $1304 \mathrm{~cm}^{-1}$

Figure 4. Difference Between the Computed and the Observed Brightness Temperatures at $1304 \mathrm{~cm}^{-1}$

Figure 5. Comparison Between the Observed and the Calculated Brightness Temperatures 
APPENDIX A

STATISTICAL BAND MODEL PARAMETERS FOR $\mathrm{CH}_{4}$ AND $\mathrm{N}_{2} \mathrm{O}$ 


\section{APPENDIX A \\ STATISTICAL BAND MODEL PARAMETERS FOR $\mathrm{CH}_{4}$ AND $\mathrm{N}_{2} \mathrm{O}$}

The absorption bands of methane and $\mathrm{N}_{2} \mathrm{O}$ of relevance to the present study have been investigated among others by Burch et al., 1962, in the laboratory for several path lengths and pressures. Their measurements were made with a spectral resolution of about $10 \mathrm{~cm}^{-1}$ which is crude for the purpose of explaining the IRIS spectra having a resolution of $2.8 \mathrm{~cm}^{-1}$. Absorption spectra in our laboratory were obtained (Blaine and Hovis, 1973) for $\mathrm{CH}_{4}$ and $\mathrm{N}_{2} \mathrm{O}$ with a resolution of $2.8 \mathrm{~cm}^{-1}$. With the help of both these sets of data we are able to fit the absorption bands of $\mathrm{CH}_{4}$ and $\mathrm{N}_{2} \mathrm{O}$ to a statistical band model (Goody, 1964). The band model permits us to express the transmission $\tau$ as

$$
\tau=\operatorname{Exp}\left[-\mathrm{kw}\left(1+\frac{\mathrm{kw}}{4 \alpha_{0} / \delta \mathrm{p} / \mathrm{p}_{0}}\right)^{-1 / 2}\right]
$$

where $\mathrm{k}$ is the absorption coefficient $\left(\mathrm{atm}^{-1} \mathrm{~cm}^{-1}\right)$,

$\mathrm{w}$ is the absorber path $(\mathrm{atm} \mathrm{cm})$,

$\alpha_{\mathrm{o}}$ is the line half width at STP $\left(\mathrm{cm}^{-1} \mathrm{~atm}^{-1}\right)$,

$\delta$ is the average line spacing $\left(\mathrm{cm}^{-1}\right)$,

$\mathrm{p}$ is the pressure and $\mathrm{p}_{0}$ the standard pressure $(\mathrm{mb})$.

The various band model parameters that have been used to compute $\mathrm{CH}_{4}$ and $\mathrm{N}_{2} \mathrm{O}$ spectrum are listed in Tables A-1 and A-2. 
Table A-1

\begin{tabular}{|c|c|c|c|c|}
\hline \multirow[b]{2}{*}{$\begin{array}{l}\text { Wave } \\
\text { number } \\
\left(\mathrm{cm}^{-1}\right)\end{array}$} & \multicolumn{2}{|c|}{ M E T H A N E } & \multicolumn{2}{|c|}{ NITROUS OXIDE } \\
\hline & $\begin{array}{l}\text { Absorption } \\
\text { coefficient } \\
\left(\mathrm{atm}^{-1} \mathrm{~cm}^{-1}\right)\end{array}$ & $\begin{array}{c}\text { Absorption } \\
\text { for } 1.1 \mathrm{~atm} \mathrm{~cm} \\
\text { of methane at a } \\
\text { pressure of } 0.5 \mathrm{~atm}\end{array}$ & $\begin{array}{c}\text { Absorption } \\
\text { coefficient } \\
\left(\mathrm{atm}^{-1} \mathrm{~cm}^{-1}\right)\end{array}$ & $\begin{array}{c}\text { Absorption } \\
\text { for } 0.25 \mathrm{~atm} \mathrm{~cm} \\
\text { of nitrous oxide at a } \\
\text { pressure of } 0.5 \mathrm{~atm}\end{array}$ \\
\hline 1210.6 & 0.23 & 0.078 & 0.018 & 0.012 \\
\hline 1213.0 & 0.01 & 0.016 & 0.018 & 0.012 \\
\hline 1222.0 & 0.36 & 0.100 & 0.100 & 0.023 \\
\hline 1226.0 & 0.04 & 0.040 & 0.145 & 0.035 \\
\hline 1231.0 & 0.85 & 0.153 & 0.230 & 0.054 \\
\hline 1234.4 & 0.04 & 0.038 & 0.240 & 0.066 \\
\hline 1238.0 & 1.32 & 0.184 & 0.430 & 0.088 \\
\hline 1239.6 & 0.20 & 0.085 & 0.480 & 0.100 \\
\hline 1243.2 & 0.92 & 0.160 & 0.670 & 0.127 \\
\hline 1244.5 & 0.46 & 0.110 & 0.740 & 0.140 \\
\hline 1248.0 & 1.54 & 0.200 & 1.040 & 0.175 \\
\hline 1251.5 & 0.09 & 0.050 & 1.320 & 0.215 \\
\hline 1255.5 & 2.02 & 0.225 & 1.940 & 0.270 \\
\hline 1257.5 & 0.17 & 0.066 & 2.280 & 0.300 \\
\hline 1262.0 & 2.62 & 0.250 & 3.360 & 0.372 \\
\hline 1267.5 & 0.80 & 0.147 & 5.450 & 0.465 \\
\hline 1270.0 & 2.62 & 0.250 & 6.620 & 0.503 \\
\hline 1271.3 & 1.50 & 0.198 & 7.200 & 0.520 \\
\hline 1273.0 & 2.42 & 0.240 & 8.350 & 0.548 \\
\hline 1274.0 & 0.15 & 0.062 & 8.600 & 0.558 \\
\hline 1276.5 & 0.85 & 0.152 & 9.900 & 0.588 \\
\hline 1278.5 & 2.00 & 0.220 & 8.720 & 0.560 \\
\hline 1280.0 & 0.14 & 0.060 & 7.800 & 0.537 \\
\hline 1284.6 & 4.03 & 0.302 & 5.200 & 0.455 \\
\hline 1286.0 & 0.14 & 0.060 & 4.300 & 0.417 \\
\hline 1290.5 & 3.41 & 0.280 & 5.050 & 0.448 \\
\hline 1292.5 & 0.46 & 0.110 & 6.350 & 0.494 \\
\hline 1296.2 & 4.51 & 0.318 & 8.600 & 0.554 \\
\hline 1297.5 & 3.89 & 0.296 & 9.000 & 0.568 \\
\hline 1299.0 & 6.21 & 0.362 & 10.000 & 0.590 \\
\hline 1300.5 & 5.41 & 0.342 & 11.000 & 0.606 \\
\hline 1304.3 & 138.00 & 0.880 & 13.000 & 0.640 \\
\hline 1308.2 & 0.01 & 0.022 & 9.700 & 0.582 \\
\hline 1311.0 & 0.33 & 0.096 & 6.850 & 0.510 \\
\hline 1313.5 & 0.02 & 0.026 & 5.800 & 0.478 \\
\hline 1317.0 & 0.33 & 0.095 & 5.450 & 0.465 \\
\hline 1322.0 & 0.83 & 0.151 & 3.100 & 0.352 \\
\hline 1324.0 & 0.14 & 0.060 & 2.280 & 0.300 \\
\hline
\end{tabular}


Table A-1 (Continued)

\begin{tabular}{ccccc}
\hline \multirow{2}{*}{$\begin{array}{c}\text { Wave } \\
\text { number } \\
\left(\mathrm{cm}^{-1}\right)\end{array}$} & $\begin{array}{c}\text { Absorption } \\
\text { coefficient } \\
\left(\mathrm{atm}^{-1} \mathrm{~cm}^{-1}\right)\end{array}$ & $\begin{array}{c}\text { Absorption } \\
\text { for 1.1 atm cm } \\
\text { of methane at a } \\
\text { pressure of } 0.5 \mathrm{~atm}\end{array}$ & $\begin{array}{c}\text { Absorption } \\
\text { coefficient } \\
\left(\mathrm{atm}^{-1} \mathrm{~cm}^{-1}\right)\end{array}$ & $\begin{array}{c}\text { Absorption } \\
\text { for 0.25 atm } \mathrm{cm} \\
\text { of nitrous oxide at a } \\
\text { pressure of } 0.5 \mathrm{~atm}\end{array}$ \\
\hline 1327.0 & 3.62 & 0.287 & 1.440 & 0.225 \\
1329.0 & 0.20 & 0.068 & 1.040 & 0.178 \\
1333.0 & 6.44 & 0.366 & 0.520 & 0.105 \\
1334.5 & 0.36 & 0.100 & 0.400 & 0.082 \\
1338.0 & 5.98 & 0.358 & 0.190 & 0.045 \\
1340.5 & 0.74 & 0.141 & 0.100 & 0.025 \\
\hline
\end{tabular}

Table A-2

\begin{tabular}{cccc}
\hline M E T H A N E & N I T R O U S O X I D E \\
\hline$\alpha_{0}=\begin{array}{l}0.085 \text { atm (Varanasi } \\
\text { and Tejwani, 1972) }\end{array}$ & $\alpha_{0}=\begin{array}{l}0.152 \mathrm{~atm} \text { (Goody } \\
\text { and Wormell, 1951) }\end{array}$ \\
$\delta \quad \begin{array}{l}5.8 \mathrm{~cm}^{-1} \text { (Nielsen } \\
\text { and Nielsen, 1935) }\end{array}$ & $\delta$ & $\begin{array}{l}0.836 \mathrm{~cm}^{-1} \text { (Goody } \\
\text { and Wormell, 1951) }\end{array}$ \\
$\alpha_{\mathrm{o}} / \delta=\begin{array}{l}0.015 \text { atm cm } \\
\text { (Adopted value) }\end{array}$ & $\alpha_{\mathrm{o}} / \delta=\begin{array}{l}0.18 \mathrm{~atm} \mathrm{~cm} \\
\text { (Adopted value) }\end{array}$ \\
\hline
\end{tabular}

